\title{
Current Federal and State Immigration Policy in the U.S. On Un-Documented and Documented Immigrants: Implications for Economic Hardship, Mental Health, Community and Family Stability
}

\author{
Peter Kamps \\ Department of Family and Support Services, City of Chicago, USA
}

\begin{abstract}
State legislation and federal immigration policy in the United States plays a pivotal role in terms of influencing the economic well-being and the associated behavioral health and mental health outcomes within the immigrant population. Federal welfare administrative changes directed at noncitizens, designed to inhibit utilization of U.S. assistance programs such as the Temporary Assistance to Needy Families (TANF) and Medicaid programs, has had a chilling effect upon access to "safety net" programs available to the low-income documented and un-documented population at large. More importantly, these policies undermine family economic mobility and community stability. This includes restrictions in employment supports resulting in lost labor productivity. This paper will examine the preliminary effects of current immigration policy, including the recently enacted "public charge" rule at the federal level. A systematic discussion of federal immigration policy, affecting immigrant access and utilization of health care resources, public benefits, housing, and employment will be examined. An analysis of the public charge federal legislation and state immigrant "safety net" policies utilizing the National Association of State Legislatures database is included. Finally, a discussion of the overall economic consequences associated with restrictive federal policy within the immigrant community, as well as the alignment of innovative state responses, will be provided.
\end{abstract}

Keywords: immigration, policy, poverty, legislation, public benefits

\section{Introduction}

Negative public perceptions of persons newly arrived within the United States and recently enacted legislation targeted towards immigrants in the arena of public benefits has played a significant role in declining immigrant enrollment rates for social welfare programs. The changing landscape towards vulnerable immigrants has significant ramifications to the health and well-being of these low income families as well as U.S. society as a whole.

On February 21 2020, the Supreme Court of the United States overturned U.S. federal district court decisions in both New York and Illinois to block the implementation of a revised public charge rule, allowing the new policy to take hold nationwide. This ruling will have far reaching implications for the overall health and well-being of immigrants within the United States.

Recent developments in U.S. immigration policy, as well as modifications in safety net program eligibility requirements for low income documented and undocumented immigrants, are likely to reverse an existing trend of a declining poor immigrant population. Numerous studies of cash and non-cash assistance programs have reported a high degree of effectiveness of these federal initiatives in lifting the number of low income individuals out of poverty, including immigrants (Trisi 2019, Wheaton 2011 \& Haveman, 2015).

Between 2016 and 2018, the number of immigrants below the poverty level decreased nationally by $7 \%$ percent. This is, in part, owing to state legislative efforts to address a widening funding gap or cuts at the federal level for social welfare programming. These state initiatives have proven critical in terms of addressing household economic stressors while augmenting declining federal safety net resources. 
The purpose of this paper is threefold: Utilizing federal administrative data, provide high level take-aways regarding the impact of the public charge rule in reducing immigrant access to safety net programs; provide an in-depth analysis of the relevant academic research which assesses the mental and physical ramifications of declining immigrant enrollment in Medicaid, the Supplemental Nutrition Assistance Program or SNAP, Subsidized housing, and employment. This paper will also evaluate the predominance of existing state legislation in the wake of new restrictive policies affecting low income documented and undocumented immigrants.

Immigrants continue to remain under-represented in the overall U.S. poverty rate, $11.0 \%$ vs. $14.6 \%$ for the population overall. (U.S. Bureau of the Census, ACS 5 Year Estimates, 2017). Aligning with the decrease in immigrant poverty has been a decade-long decrease in the national safety net expenditure rate for low income immigrants utilizing U.S. public assistance. This has accelerated over the past several years. Programs such as Medicaid, Housing Assistance, the Supplemental Nutrition Assistance Program (food stamps), and Temporary Assistance to Needy Families (TANF) have all witnessed declines in immigrant utilization.

The number of documented and undocumented immigrants within the United States has similarly decreased, from approximately 47.7 million in 2015 to 45.6 million in 2017. The number of non-naturalized immigrants below the federally designated poverty level has also declined during this time period, from 5.4 million in 2015 to 5.0 million in 2017 .

Despite the decrease in poverty within this population, a declining safety net enrollment rate, and the fact non U.S. citizens utilize public assistance at a lower rate than their U.S. citizen counterparts, significant concern has been raised over the likelihood immigrants will become a burden to the U.S. taxpayer. (Zu et. al. 2015, Campbell, 2012, Ingram, 1993). This concern, along with political developments within the United States regarding immigration, has led to an expansion of the so called public charge rule. These new policies have the potential of negatively influencing the overall mental health and health of the undocumented and documented immigrant population.

This paper will examine the mental health and health impact of the "public charge" rule in terms of lack of access to key safety net programming within the documented and undocumented immigrant population. Enrollment trends of immigrant utilization within three key public benefit areas, Medicaid, Food Assistance, and housing, due to modifications in the public charge rule, are presented. A discussion of employment patterns as well as the economic ramifications within the low income documented and undocumented population within the U.S. will be included. Finally, an analysis of state legislative response in mitigating the harsh realities of the revised federal immigration policy will also be covered.

\section{Research Methodology}

The social construction or perception within the overall U.S. population of behaviors associated with low income immigrants (i.e.laziness, lack of motivation to become gainfully employed, willingness to take advantage of public benefits) as well as implementation of an expanded public charge rule has resulted in a rapidly declining public assistance utilization rate for these vulnerable residents.

In order to gain better insight into how negative public perceptions of immigrants as well as legislative policies have affected immigrant enrollment in safety net programming, administrative data from the Current Population Survey or CPS (U.S. Department of Labor) and the American Community Survey or ACS, was collected for the most recent years available. This data was collected at both the national level and for the largest U.S. cities for which data was available (New York City and Chicago). In addition, immigrant safety net enrollment projections utilizing both ACS and CPS data were developed for this paper. These data sources were selected since it provides a higher degree of clarity as to how immigrants are utilizing these programs within all 50 states. National administrative data can provide high level takeaways to understand the scope of the issue within 
the U.S. To better understand the mental health and health ramifications of declining public safety enrollment patterns, a robust review of academic literature is also included.

\section{History Of Public Benefits Eligibility For Immigrants In The U.S.}

Current federal immigration policy regarding public benefits originated in the Personal Work Opportunity and Reconciliation Act (PRWORA) of 1996 under the Clinton Administration and the Illegal Immigration Reform and Immigrant Responsibility Act (IIRIRA) of 1996. These laws together determine immigrant access and eligibility to "safety net" programming. Prior to implementation of the PRWORA act, immigrants were accessing safety net programming at a much higher rate. (Hagan 2003).

Two primary categories of assistance are covered under these pieces of legislation, cash assistance and non-cash assistance. Cash assistance programs include the Supplemental Security Income program (SSI) and the Temporary Assistance for Needy Families (TANF) programs. Non cash assistance programs include Medicaid, Housing subsidy programs such as Section 8 as well as public housing. Other non-cash assistance programs include the Supplemental Nutrition Assistance Program (SNAP), and the Children's Health Insurance Program (CHIP). The two laws limit enrollment in any of these programs to legal residents within the United States, including immigrants who have long-term residency status (LTR) or a green card, and refugees/people under asylum who qualify within income guidelines. Most states require legal residency for immigrants for five years, before they become eligible for these federal programs. These laws only allow for un-documented and other immigrants, access to emergency Medicaid services (such as payment for hospital emergency room visits), and enrollment in the Women, Infants and Children emergency food program (WIC). The Affordable Care Act (ACA) similarly limits health insurance enrollment to qualified and eligible immigrants.

Another key component of the 1996 legislation was the creation of two classes of non U.S. citizens, qualified and non-qualified immigrants. This distinction was developed as the primary determining factor of whether a non U.S. Citizen could apply and receive a safety net benefit (Pew Charitable Trust 2014)

Qualified immigrants are those who are lawfully present within the United States (hold a green card), refugees, and those who are granted asylum. Non-citizens who do not meet these criteria are considered unqualified immigrants (some temporary workers, students and tourists, people granted temporary protected status, and unauthorized immigrants). Qualified immigrants may enroll and receive federal public benefits if they meet specific income and residency requirements. Non-qualified immigrants are generally excluded from any federally sponsored safety net program (although some states have compensated for this by developing their own support programs for low income immigrants, described later in this paper).

Research has shown the expenditure rate within the documented and undocumented immigrant population for programs such as Medicaid, the Children's Health Insurance Program (CHIP), Supplemental Security Income (SSI) and the Supplemental Nutrition Assistance Program (SNAP) is much lower for these individuals than their U.S. native counterparts (O'Shea 2018). Studies have also indicated that immigrants contribute more to government revenue overall and social capital than they expend in terms of safety net usage. (Lowrey et. al. 2018 ). Despite these trends, a national decrease in the immigrant utilization rate within key safety net initiatives has accelerated since the passage of the PRWORA act. This has continued since the transition from the prior federal administration to the current Trump administration. Part of this reasoning may include the desire to remain gainfully employed while remaining in the U.S within the immigrant population.

Immigrants may prioritize the ability to legally work within the United States over enrollment in safety net programming. Research has shown the ability to legally work within the United States and a pathway to citizenship was valued more highly than being able to enroll in public safety net programs (Melo, et. al, 2014). However, for un-documented and documented individuals facing prolonged economic hardship, the expanded 
public charge rule may result in far reaching consequences to their ability to care for themselves and their families

\section{Public Charge Rule}

The public charge rule defines someone who either wishes to gain entry into the United States or a non-U.S. citizen seeking long term residency status (or green card) within the U.S. and is considered likely to become a public burden to the U.S. taxpayer. Public charge is determined either through enrollment in a public cash assistance program for income maintenance or enrollment in a variety of non-cash transfer programs such as Medicaid (the primary method by which low income individuals can access health care), subsidized housing programs, or food assistance.

During 2019, the Trump administration announced a final rule which modifies the public charge policies used to determine whether an individual applying for admission or adjustment towards legal status is inadmissible to the United States. Under the rule, the federal government can deny an individual entry into the U.S. or make an adjustment to their residency status (green card), adjust their legal permanent residency status (LPR) status or a green card if he or she is determined to be a public charge. This rule was upheld by the U.S. Supreme Court during February, 2020.

Prior to the Expanded Public Charge rule, the previous policy covered the following programs in Public Charge Determinations: SSI, Temporary Assistance to Needy Families (TANF), State or Local Cash Assistance Programs and Public Assistance for long term care in an institution such as a nursing home, including Medicaid. The new policy adds to the already existing programs to be considered in any public charge rule the following: Non-Emergency Medicaid (for non-pregnant adults over age 21), SNAP food assistance, and Housing Assistance.

Thus, under the new public charge rule, immigrant enrollment in such safety net programs as Medicaid, SNAP (food assistance), and housing assistance is viewed negatively when an immigrant is applying for green card status, thus potentially derailing a path to citizenship. One of the consequences of the new rule is a likely acceleration of declining enrollment within Medicaid within the low income immigrant population and participation in other safety net programs. This trend is already evident when examining recent administrative data from the Current Population Survey.

Decreased participation in Medicaid, subsidized housing and food assistance programs would contribute to increased economic hardship, increased stress within the family unit, as well mental health issues within the low income immigrant community. More significantly, these changes would likely increase the number of immigrants below the poverty level within the United States with implications for lost labor productivity to the U.S. economy.

Many immigrants seeking an improved life by relocating to the U.S. are confronted with an array of economic challenges. Close to eighty percent of non-citizens who originally entered the U.S. without LPR status have at least one characteristic that the Department of Homeland Security (DHS) could potentially weigh negatively in a public charge consideration. This includes lack of educational attainment (not having a high school diploma) or private health insurance. (Artiga et. al. 2019) In other words, when considering whether to grant an immigrant permanent residency status, a majority of these immigrants are already vulnerable to losing long-term residency.

A Kaiser Foundation study conducted during 2019 found more than 56\% of non-citizens in the U.S. are lacking private health insurance and close to $40 \%$ do not have a high school diploma (Garfield et. al 2019). Close to one-third of the immigrant population who entered the United States have a family income below the 125\% poverty threshold. ( $\$ 32,187$ for a family of four in 2019). All these factors are weighed when factoring in long term admissibility into the United States. 
Although most states require a five year residency prior to an immigrant becoming eligible for one of these federal programs, any attempt at participation would possibly service as a "tipping point" towards exclusion, ultimately resulting in their deportation to the country of origin. Similarly, enrollment in public assistance could result in the denial of entry within the United States. The three federal social welfare programs affected by the expanded public charge rule are Medicaid, Housing Assistance and the Supplemental Nutrition Assistance Program (SNAP) are described below.

\section{Impact On Medicaid Enrollment}

According to the U.S. Bureau of the Census, the number of eligible immigrants who were below $138 \%$ of the poverty level and utilized Medicaid decreased by $10 \%$ between 2016 to 2018. Medicaid is the federal program through which low income individuals can gain access to health care services within the United States. A decrease in Medicaid enrollment for low income immigrants is likely to result in poor health outcomes, affecting the overall health of this population, as well as adding to an overall increase in national health care costs due to hospitalizations and increased emergency room visits.

Bernstein, et. al. (2019), in his national immigration survey conducted prior to the final rule, found that one in seven immigrant adults reported avoiding public benefit programs for fear of risking future green card status, and more than one in five adults in low-income immigrant families reported this fear. Berk (2004) in a 1996 study of 710 Latino immigrants which utilized in-person interviews, found that $39 \%$ of the respondents in Houston, El Paso, Fresno and Los Angeles who were undocumented were fearful of utilizing health services due to their immigration status.

Other researchers have similarly documented a future decrease in Medicaid immigrant enrollment due to the public charge rule (Perriera, K, 2018, Canady, 2020, Garfield, 2019, Schlosberg and Wiley, 1998). Based upon methodology developed by the Kaiser Foundation (Artiga, 2019), the projected decrease in immigrant Medicaid enrollment in New York City alone could result in 55,000 low income immigrants alone who would qualify for subsidized health insurance disenrolling.

Table 1-Estimated Disenrollment in Medicaid for Eligible Immigrants Due to Public Charge Rule: New York and Chicago

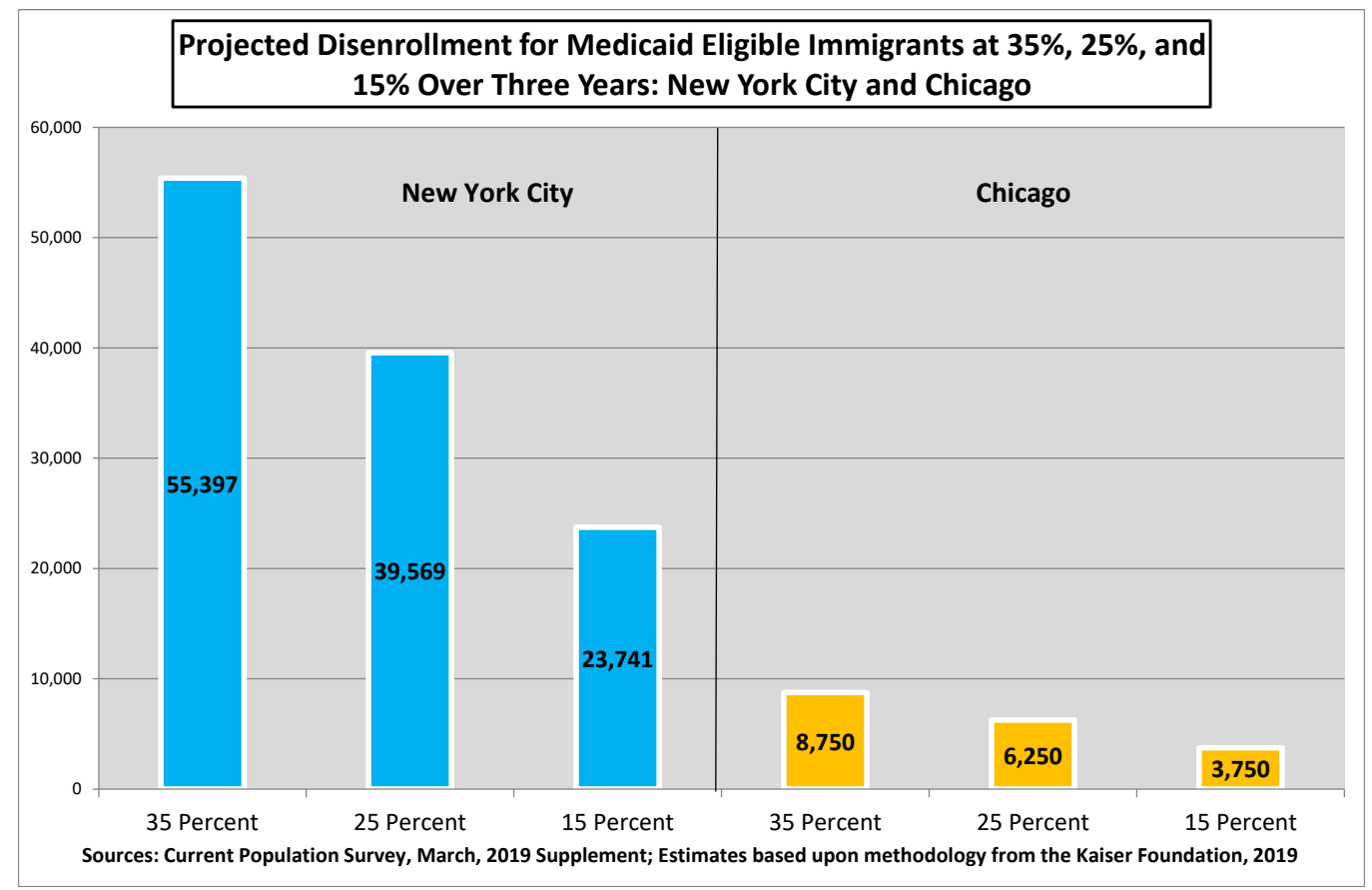


Utilizing Current Population Survey (CPS) data from the U.S. Census Bureau, it is possible to estimate the total pool of immigrants who are either un-documented or documented and eligible for Medicaid, based upon income (138\% or below poverty). The CPS does not differentiate between the various sub-populations within the immigrant community, including persons seeking asylum within the United States or refugees who may immediately qualify for public safety net programs. However, national demographic data corroborates the theory of declining enrollment due, in part, to fears within the immigrant community of losing permanent residency status as well as negative public perceptions of immigrants.

The next graph illustrates the number of Non-U.S. citizens within New York City and Chicago (cities for which data was available) and the actual number of low income immigrants not enrolling in Medicaid. The bar represents number of documented and undocumented immigrants in New York and Chicago and the yellow trend line indicates income eligible who are not enrolled in Medicaid.

Table 2-Trends in Medicaid Enrolment for Eligible Un-Documented and Documented Immigrants: 2016-2018: Chicago and New York City

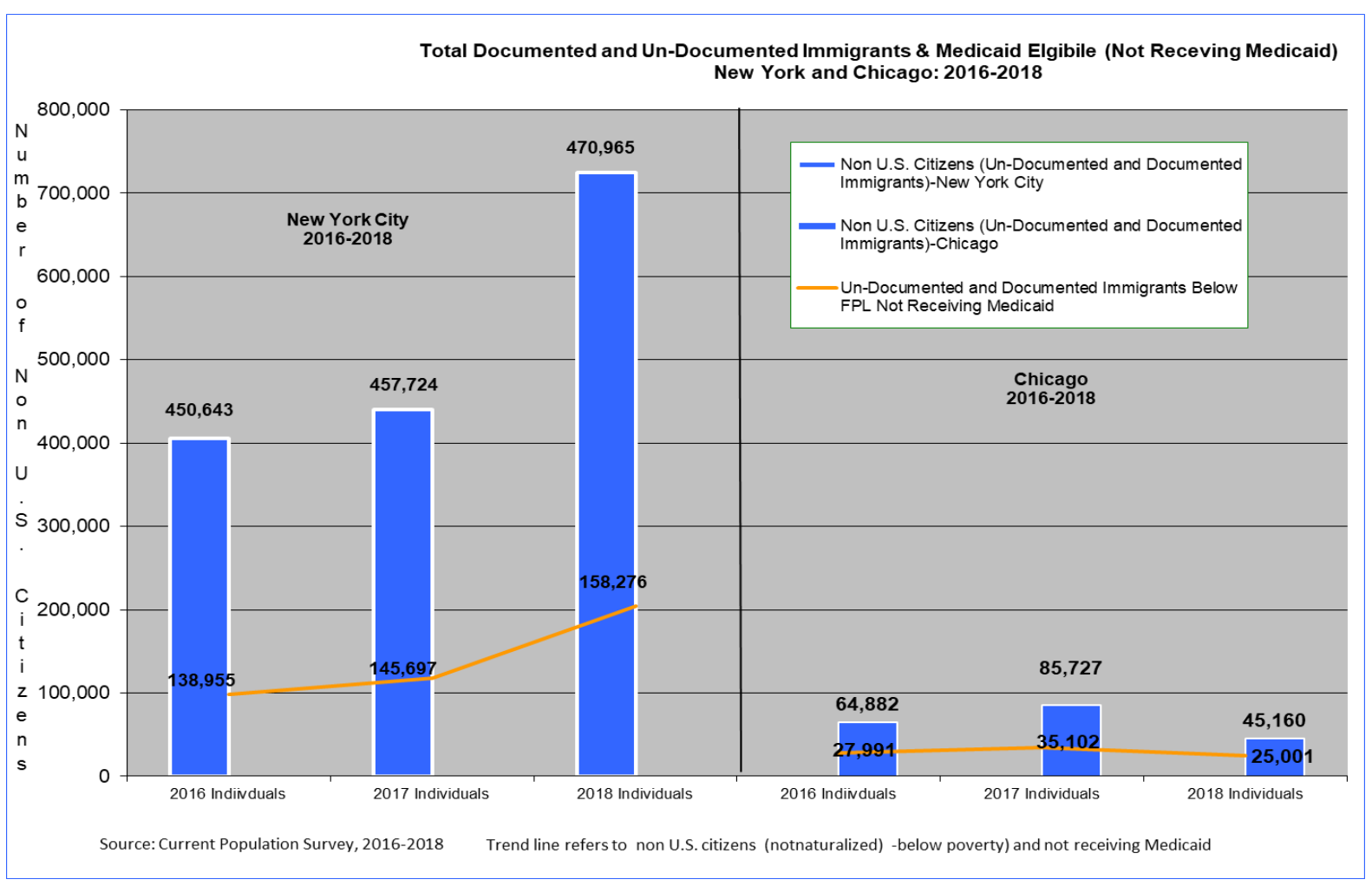

Recent research and anecdotal evidence suggests the expanded public charge rule will have a chilling effect on immigrant families, leading them to forgo enrollment in a necessary safety net program due to confusion or fear that their child's enrollment could ultimately result in deportation or denial of long term residency. Bernstein et. al (2019), in his study of immigrant safety net enrollment trends, provides reports of low income immigrant families choosing not to enroll their children in the Children's Health Insurance Program (CHIP) and themselves in Medicaid. Negative consequences associated with residency status played a significant role in the parent's decision-making. The expanded public rule is likely to accelerate this trend. In addition, as low income families seek out alternative health care resources, private not-for-profit health care organizations are more likely to become overburdened. 
The Kaiser Foundation has estimated there are at least 7.6 million children, who are noncitizens and who may be at risk for decreased health care enrollment as a result of revised federal immigration policy. In addition, according to American Community Survey data from the U.S. Census Bureau, there were over 13.5 million Medicaid/CHIP enrollees who were noncitizens or citizens living in a household with at least one citizen who may be at risk for decreased enrollment due to the expansion of the public charge rule. The Kaiser Foundation estimates at least 2.0 million to 4.7 million Medicaid and CHIP enrollees would dis-enroll nationally (15 percent to 35 percent of the eligible Medicaid non-citizen population) upon implementation of this policy.

\section{Food Assistance}

Prior to the expanded public charge rule, immigrants who were lawfully within the United States faced no negative consequences if they enrolled within the Supplemental Nutrition Assistance Program (SNAP), the primary means whereby low income immigrants can gain access to food assistance within the U.S. The new law reverses this policy, opening up the possibility a family can be deported if they require and enroll in federally sponsored emergency food assistance. In addition, since unauthorized immigrants often apply for safety net programs on behalf of their children who are eligible, these parents may decide not to enroll in order to keep the family unit intact. This would place the children at risk of poor health outcomes, cognitive development issues, and other negative developmental outcomes. According to the U.S. bureau of the Census, the percentage of immigrants who were either undocumented or documented and were receiving SNAP benefits as of December, 2017 has already declined by a substantial margin over the past several years.

A primary purpose of the Supplemental Nutrition Assistance Program is to lift individuals who qualify out of poverty. As described earlier, recent studies have shown safety net programs to be effective in accomplishing upward economic and social mobility (Trisi 2019, Huang et. al. 2018). Conversely, by potentially denying immigrants a path to citizenship by monitoring safety net usage, this policy may result in the acceleration of immigrants who choose not to seek out assistance, thereby contributing to financial hardship and financial instability within households. Immigrant participation in food assistance plays a critical role in reducing food insecurity, thereby promoting their overall health and well-being. Growing mistrust in government programs, owing to putative government policies towards economically vulnerable non U.S. citizens, may also contribute to a decrease in enrollment within critical safety net programs such as SNAP. This trend is substantiated by administrative data from the U.S. Census Bureau.

Between 2016 and 2018, the percentage of non-U.S. citizens below 150\% of the poverty line utilizing SNAP benefits decreased by $27 \%$ A decrease in SNAP participation within the low income immigrant population is also likely to create an added strain upon charitable food organizations. New York City has already reported a substantial decline in SNAP immigrant benefit utilization, declining 26\% over the past several years as well as an increase in emergency food bank usage (Food Bank for New York City, 2020).

Food insecurity has been associated negatively with child development and health. (Huang, et al., 2010) Results from a 2018 study of food insecurity among immigrants indicated children from food insecure immigrant families fare far worse in terms of health outcomes than non-immigrant families within the United States. However, Huang et. al. (2010), found children of immigrants in families experiencing economic hardship, although faring worse in terms of health outcomes, showed little difference in terms of cognitive development. Low socioeconomic status within the immigrant population may exacerbate the health consequences of food insecurity within the immigrant child population. (Public Health Nursing, 2018)

Food insecurity has also been linked to poor diet, chronic diseases and health disorders (Seligman et. al. 2010). This in turn, is likely to result in increased hospital emergency room visits. According to a recent study completed on the health care expenditures from poor health in Chicago (Sorrentino, Kamps et. al, 2017), the average public hospital stay cost for a low income individual as a result of chronic heart disease was 
approximately $\$ 102,000$, for diabetes, the annual cost was approximately $\$ 26,000$ and for stroke, the annual cost approached $\$ 44,000$. Denial of these benefits to the low income immigrant population will likely result in high national medical expenditures, the burden of which will ultimately fall upon hospitals and U.S. taxpayers.

\section{Housing Assistance}

Under the expanded public charge rule, utilization of federal subsidized housing programs including Section 8 housing choice vouchers, Section 8 Project-Based Rental Assistance, or public housing would be factored in when an immigrant is seeking long term residency status (LTR). Occupancy in such housing units which fall under the various government sponsored programs would thereby be deemed a negative factor in weighing whether an individual would be allowed to remain within the United States. As with other social welfare programs, the percentage of low income non-U.S. citizens utilizing housing assistance has already decreased by a substantial margin (Current Population Survey, 2016-2018).

Chicago and New York City also reported a significant decrease in the number of immigrants utilizing public housing or Section 8 housing assistance. In New York City, the number of low income immigrants utilizing housing subsidies decreased from 56,904 to 35,621 between 2017 and 2018. In Chicago, the number of low income immigrants receiving housing subsidies similarly declined from 4,882 to 3,139 during the same timeframe. New federal immigration policies prohibit mixed status families-comprised of household members who are both eligible (dependent children) and ineligible (their parents or guardian) from receiving public or other housing subsidies. This includes families who live in public housing and are using Section 8. The U.S. Bureau of Housing and Urban Development estimates at least 25,000 families nationally and 55,000 children would be evicted due to the new rule.

For low income individuals, adequate housing has been associated with improved mental health and improved health outcomes for both adults and children. (Leventhal et. al.1 2005). A key component of immigrant housing policy under the Trump Administration has been the implementation of subsidized housing policies which exclude immigrants whose households contain both documented (legal) and undocumented (illegal) individuals from occupying the same housing unit. This policy could also result in an increase in homeless individuals within the United States, raising pressure on an already overburdened U.S. shelter system.

During May of 2019, the U.S. Department of Housing and Urban Development proposed a rule which would change eligibility requirements for public housing. The new housing rule bans any immigrant family from obtaining any form of subsidized housing assistance, whether this is occupancy in public housing or a housing voucher. Prior to the implementation of this rule, an immigrant family could sign a lease on a public housing unit or receive subsidized housing assistance if at least one member was within the United States legally.

The rule would deny eligibility to a family if any member is an undocumented immigrant. Currently, an immigrant family can sign a lease on a public housing unit as long as one family member is in the United States legally, usually the dependent child of undocumented immigrants. Despite the perception of immigrant abuse, housing subsidies and public housing expenditures among immigrants remain much lower than their U.S. citizen counterparts (O’Shea, et. al, 2018).

Further analysis is needed in terms of the effect of the mixed-use housing rule, potentially increasing homelessness within the immigrant community and increasing demand within an already overburdened shelter system. Of major concern are those immigrants who are survivors of domestic violence and utilizing housing subsidies. 


\section{Employment}

Stressors associated with transitioning to a new country along with prolonged periods of unemployment have been associated with higher mental health risks within the immigrant population. (De Castro, A. Rue, T. 2010, Barnett et. al. 2008). Federal requirements for eligibility to work within the United States also may prolong unemployment as there are significant, lengthy procedural barriers for immigrants to prove they can work legally within the United States. In many instances, low income individuals who are new to the United States wind up in low wage, temporary positions, without benefits such as health care and sick leave. This includes seasonal employment (i.e., agricultural labor) or industrial positions.

Lack of employment can lead to economic hardship and the probability that a family will encounter a lengthened period of poverty. The inability to utilize an occupation skill set within the immigrant population has also been associated with poor mental health. (Reid et. al. 2012). Immigrant frustration with obtaining adequate or satisfying employment has also been linked with lowered physical health and mental health (De Castro et. al. 2010).

Given the vulnerability of immigrant families in terms of economic stressors, such as unstable or intermittent unemployment, safety net programs become even more critical in terms of importance. Despite a federal push towards disinvestment of public resources towards assisting vulnerable immigrant populations, states have proven resilient in addressing the growing need for income support within their midst.

\section{State Initiatives}

The U.S. government, in passing the 1996 welfare reform legislation, did allow states some flexibility in terms of funding immigrant programming through a combination of state revenue and federal resources. This includes non U.S. citizens who have resided lawfully within the United States for less than five years. However, eligibility remains restricted to "qualified immigrants" or individuals who can prove lawful residency within the United States.

During 2009, the federal government passed the Children's Health Insurance Program Reauthorization Act (CHIPRA) to allow states to provide medical coverage through Medicaid and the Children's Health Insurance Program (CHIP). This allows female immigrants who were pregnant and their children who were lawfully residing within the United States to receive medical coverage without the standard five year residency waiting period. Included in the CHIPRA program is a financial incentive for states to provide an increased federal match rate for children under age 19. This has proven effective in improving the overall health coverage of children and likely facilitated improvements in the overall health of the immigrant family unit. (Saloner B. et. al. 2015).

In addition, there are twenty six states as of May, 2014 who provide state-only funding for immigrant safety net programs which emulate federal assistance programs in the areas of healthcare access, income transfer, food assistance, as well as assistance to the elderly and disabled. The most widely available program mirrors the Temporary Assistance to Needy Families (or TANF program). This provides cash assistance to low income immigrants who meet certain income and work requirements. The second most widely available program is state sponsored health care assistance (offered by ten states and the District of Columbia). At the other end of the spectrum are only ten states who have not taken up one of the federal state options to expand eligibility for immigrants in the area of health care.

States also vary widely on what types of safety net benefits they offer to immigrants in the areas of health care, cash assistance, as well as food assistance. Some states may extend all state-funded benefits to all non U.S. citizens, irrespective of their status. Other states confine state funded benefits to a specific sub-population within the immigrant community. Further research is needed to determine if the expanded federal public charge rule may affect enrollment within state-funded only programs due to fears within the immigrant community, This 
will likely shift the overall cost burden of offering Medicaid coverage for immigrants away from the federal government and on to the states themselves.

In order to mitigate increased federal scrutiny and restrictions in terms of safety net programs within the immigrant community, at least 37 states considered and/or passed sanctuary legislation during 2017. This is designed to protect the identity of undocumented and documented immigrants, and limits state cooperation with federal immigration officials. The state of Illinois enacted the Trust Act, prohibiting state enforcement of federal civil immigration laws, without restricting communication on immigrant status required under certain provisions of Title 8 within the U.S. code. New York passed similar legislation. These actions (provisions 1373 and 1644), prohibit local and state governments from enacting laws that limit communication with the Department of Homeland Security regarding the immigration or citizenship status of individuals. However, the policy does not contain any requirement for anyone to initiate or take any action to disclose an individual's immigration status.

The District of Columbia recently also enacted legislation supporting sanctuary policies, thus limiting cooperation with Immigration and Customs Enforcement personnel (I.C.E.).Sanctuary policies generally limit state and jurisdictional cooperation with federal immigration officials, particularly regarding the disclosure of immigrant status. Other states such as Texas, Georgia, Indiana and Mississippi have enacted legislation opposing immigrant sanctuary policies.

It is unclear at the time of this writing whether enrollment in any of these state sponsored public benefit programs would be weighed negatively under the expanded public charge rule when determining whether an immigrant could be granted permanent green card status. As discussed earlier, states such as Illinois and New York have passed state legislation which does not require local officials to initiate the disclosure of a particular individual's immigrant status, thereby rendering them potentially "invisible" in any public charge determination.

\section{Conclusion}

There continues to be a large body of demographic evidence and academic research to support a clear association between declines in immigrant safety net program participation or voluntary non-enrollment and the fear of losing long-term U.S. residency. Further restrictions as evidenced by the expanded public charge rule are likely to accelerate this trend. Longer term negative consequences for the mental, physical and economic wellbeing of vulnerable non U.S. citizens are likely to accrue as a result

Conversely, immigrant participation in food programs such as the Supplemental Nutrition Assistance Program has been associated with improvement in birth outcomes and the cognitive development of children (Fleischhacker, S. et. al. 2019). Immigrants who participate in CHIPRA health programs have demonstratively improved health care coverage and better health outcomes in comparison to those who choose not to enroll. (Saloner B, et. al. 2018, Reich, G. 2018). Individuals who are in more stabilized housing situations and reside in economically stable neighborhoods are less likely to report anxiety and depressive symptoms (Katz et. al. 2000). Hence, allowing immigrants access to subsidized housing in safe neighborhoods offers a clear path to ensuring the integrity of the family unit.

Decreased immigrant participation in public safety net programs, and increased reliance upon earnings alone, will have significant consequences to the overall health of the U.S. economy by increasing the length an immigrant household will remain in poverty. In addition, the revised public charge rule will likely shift the immigrant cost burden from the federal government to states which have safety net programs that emulate national welfare programs. This undermines any cost savings to the U.S. taxpayer which will be achieved through implementation of the expanded federal policy.

With the advent of the Covid-19 global pandemic, further research is necessary regarding immigrant fears associated with utilizing public health care resources and how this may affect the overall course of transmission 
within not only the immigrant community, but also the overall population at large. Subsequent analysis of the effects of the revised public charge rule on potentially over-burdening health care organizations (i.e. Federally Qualified Health Centers), also needs to be undertaken.

Finally, despite the availability of some safety net programming offered through both federal and state governments, substantial fear and confusion over participation in public welfare programs remains within the immigrant community. Declining enrollment in federally sponsored health, housing and food assistance programs is already evident in large U.S. cities such as New York and Chicago.

Research has clearly indicated that immigrants tend to ultimately provide an economic dividend to U.S. society, through contributions in the fields of science, technology, and the arts. Immigration policies and the actions of government officials, rather than throwing up road-blocks, could facilitate the necessary supports to encourage vulnerable immigrant families to succeed. This will undoubtedly make possible, not only a heightened economic potential for newcomers to U.S. society, but help drive their contributions to humanity within subsequent generations as well.

\section{References}

American Civil Liberties Union, State and Local Immigration Laws (Website, 2019)

Artiga et. al, "Estimated Impacts of Final Public Charge Inadmissibility Rule on Immigrants and Medicaid Coverage", Kaiser Foundation Issue Brief, September, 2019.

Berk, M., \& Schur, C. (2004). The Effect of Fear on Access to Care Among Undocumented Latino Immigrants. Journal of Immigrant and Minority Health, 3(3), 151-156.

Bernstein, Hamutal; Gonzalez, Dulce, Karpman, Michael, Zuckerman, Stephen; "With Public Charge Rule Looming, One in Seven Adults in Immigrant Families Reported Avoiding Public Benefit Programs in 2018" (Washington, DC: Urban Institute, May 2019),

Bleich, S., \& Fleischhacker, S. "Hunger or Deportation: Implications of the Trump Administration's Proposed Public Charge Rule”, Journal of Nutrition Education and Behavior, 51(4), 505-509. (2019)

Campbell, A., "Policy Makes Mass Politics”, Annual Review of Political Science, 15, 333-51 (2012)

De Castro, A., Rue, T., \& Takeuchi, D., "Associations of Employment Frustration with Self-Rated Physical and Mental Health Among Asian American Immigrants in the U.S. Labor Force”, Public Health Nursing, 27(6), (2010).

FAQ ON 8 USC $\S 1373$ and Federal Funding Threats To “Sanctuary Cities”, Immigrant Legal Resource Center (April, 2017)

Fox, L., Wimer, C., Garfinkel, I., Kaushal, N., \& Waldfogel, J. (2015). Waging War on Poverty: Poverty Trends Using a Historical Supplemental Poverty Measure. Journal of Policy Analysis and Management, 34(3), 567-592.

Haveman, R., Blank, R., Moffitt, R., Smeeding, T., \& Wallace, G. (2015). THE WAR ON POVERTY: MEASUREMENT, TRENDS, AND POLICY. Journal of Policy Analysis and Management, 34(3), 593-638.

Huang, Y., Potochnick, S., \& Heflin, C. (2018). Household Food Insecurity and Early Childhood Health and Cognitive Development among Children of Immigrants. Journal of Family Issues, 39(6), 1465-1497.

Katz, L., Kling, J., \& Liebman, J. (2001). Moving to Opportunity in Boston: Early Results of a Randomized Mobility Experiment. The Quarterly Journal of Economics, 116(2), 607-654.

Leventhal, T., Fauth, R., \& Brooks-Gunn, J. (2005). Neighborhood Poverty and Public Policy: A 5-Year Follow-Up of Children's Educational Outcomes in the New York City Moving to Opportunity Demonstration. Developmental Psychology, 41(6)

Lowrey, Annie, “Are Immigrants a drain on Government Resources” (Atlantic Magazine, September, 2018)

Melo, G., Colson, G., \& Ramirez, O. (2014). "Hispanic American Opinions toward Immigration and Immigration Policy Reform Proposals. Applied Economic Perspectives and Policy”, 36(4), 604-622 (2014)

National Conference of State Legislatures, Immigration Resources (Website) 
O'shea, Tim et. al, "Immigrants and Public Benefits: What Does the Research Say?" November 2018, Bipartisan Policy Center, Tim O'shea et. al, November, 2018.

Perreira, K., Yoshikawa, H., \& Oberlander, J. (2018). A New Threat to Immigrants' Health — The PublicCharge Rule. The New England Journal of Medicine, 379(10), 901-903.

Pew Charitable Trust Brief, "Mapping Public Benefits For Immigrants Within the United States" September, 2014

Reich, G. (2018). Hitting a Wall? The Trump Administration Meets Immigration Federalism. Publius: The Journal of Federalism, AdvanceArticle(3), 1-395.

Reid, A., "Under-use of Migrants' Employment Skills Linked to Poorer Mental Health" Australian and New Zealand Journal of Public Health, 36(2), (2012)

Saloner, B., Koyawala, N., \& Kenney, G. (2015). Coverage for low-income immigrant children increased 24.5 percent in states that expanded CHIPRA eligibility.. Health affairs (Project Hope), 33(5), 832-9.

Schneider, A., \& Ingram, H., "Social Constructions of Targeted Populations: Implications for Politics and Policy” American Political Science Review, 87(2), 334-47, (1993)

Seligman et. al, "Food Insecurity Is Associated with Chronic Disease among Low-Income NHANES Participants", Journal of Nutrition, Feb. 2010

Sorrentino, Kamps et. al, "Practicing Food Justice, A Comparative Evaluation of Recent Developments in Chicago and Philadelphia", Macalester College, June, 2017

Trisi, Danilo et. al, Economic Security Programs Cut Poverty Nearly in Half Over Last 50 Years, Center for Policy and Budget Priorities, November, 2019.

U.S. Bureau of the Census, ACS 5 Year Estimates: 2015-2017

U.S. Department of Labor/U.S. Bureau of the Census, Current Population Survey, March Supplement: 20162018.

Wheaton, L., Giannarelli, L., Schiferl, M., \& Zedlewski, S. (2011). How Do States' Safety Net Policies Affect Poverty?. Poverty \& Public Policy, 3(4),

Zhu, L., \& Xu, P. (2015). The Politics of Welfare Exclusion: Immigration and Disparity in Medicaid Coverage. Policy Studies Journal, 43(4), 456-483. 